\section{Research Square \\ Preprints are preliminary reports that have not undergone peer review. \\ They should not be considered conclusive, used to inform clinical practice, or referenced by the media as validated information.}

\title{
Economic assessment of incorporating the Hexavalent vaccine as part of the National Immunization Program of Peru
}

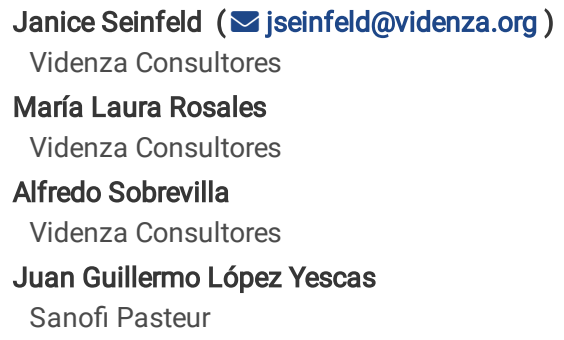

\section{Research Article}

Keywords: budget impact analysis, cost-minimization analysis, combination vaccines, acellular hexavalent vaccine, oral poliovirus vaccine, Peru, public health policy, vaccination, Expanded Program on Immunization, primary vaccination scheme

Posted Date: August 19th, 2021

DOI: https://doi.org/10.21203/rs.3.rs-757467/v1

License: () (i) This work is licensed under a Creative Commons Attribution 4.0 International License. Read Full License 


\section{Abstract \\ Background}

This study aimed to estimate the economic impact of replacing the current Peruvian primary immunization scheme for infants under 1 year old with an alternative scheme with similar efficacy, based on a hexavalent vaccine.

\section{Methods}

A cost-minimization analysis compared the costs associated with vaccine administration, adverse reactions medical treatment, logistical activities, and indirect social costs associated with time spent by parents in both schemes. A budgetary impact analysis assessed the financial impact of the alternative scheme on healthcare budget.

\section{Results}

Incorporating the hexavalent vaccine would result in a $15.5 \%$ net increase in healthcare budget expenditure $(\$ 48,281,706$ vs $\$ 55,744,653)$. Vaccination costs would increase by $54.1 \%$, whereas logistical and adverse reaction costs would be reduced by $59.8 \%$ and $33.1 \%$, respectively. When including indirect social costs in the analysis, the budgetary impact was reduced to $8.7 \%$. Furthermore, the alternative scheme would enable the liberation of $17.5 \%$ of national vaccines storage capacity.

\section{Conclusions}

Despite of the significant reduction of logistical and adverse reaction costs, including the hexavalent vaccine into the National Immunization Program of Peru in place of the current vaccination scheme for infants under 1 year of age would increase the public financial budget of the government as it would represent larger vaccine acquisition costs. Incorporating the indirect costs would reduce the budgetary impact demonstrating the social value of the alternative scheme. This merits consideration by government bodies, and future studies investigating such benefits would be informative.

\section{Background}

The National Immunization Program of the Peruvian Ministry of Health (Ministerio de Salud de Perú [MINSA]) was established in 1976 to protect the general population against vaccine-preventable diseases (1) and was most recently updated in 2018 (2). As part of this strategic healthcare intervention, all infants under the age of 1 year should be primary vaccinated against diphtheria, tetanus, hepatitis B, Haemophilus influenzae type B (Hib), and poliomyelitis by the administration of three doses of a pentavalent vaccine (DTwP-HB-Hib) plus two doses of the inactivated polio vaccine (IPV) and one dose of the oral polio vaccine (OPV) (2). These six diseases are associated with significant morbidity and mortality, particularly in infants, and maintaining high rates of immunization coverage is crucial to avoid their spread (3-8).

A hexavalent vaccine (DTaP-HB-Hib-IPV) that prevents all six diseases has been prequalified by the WHO (9). Various clinical trials performed in Latin America have reported its high level of immunogenicity $(>95 \%)(10,11)$ and, it is already part of national vaccination programs across most European countries, as well as Canada, Panama, and Chile (12-15). In Peru, its use has been approved, although it is only available in the private market (16).

The composition of the hexavalent vaccine (17) provides several benefits, most importantly the fact that it eliminates the risk of contracting vaccine-derived poliovirus (18). The OPV utilizes a live-attenuated poliovirus and presents a high risk of fecal-oral transmission, increasing the potential for cases of circulating vaccine-derived poliovirus (19). In contrast, the IPV-containing hexavalent vaccine represents an alternative to stop the occurrence of vaccineassociated paralytic poliomyelitis (18).

In addition, being a combination vaccine, the hexavalent vaccine could reduce the burden of multiple injections and provide better acceptance from parents, (20) in turn improving compliance and timeliness of vaccination (21). Nevertheless, a more integrated scheme also entails some limitations such as greater sensibility to supply interruptions (22) and higher acquisition prices (23).

Considering Peruvian healthcare budget constraints and the importance of strengthening financial sustainability for immunization programs, the evaluation of the economic impact of incorporating this new scheme in Peru is of high interest for the payer. Because the two schemes have been shown to have similar efficacy, the following comprehensive economic assessment consists of a cost-minimization analysis (CMA) comparing the costs associated with the current Peruvian primary immunization scheme with those of the hexavalent-based scheme, from a social perspective. Furthermore, a budgetary impact analysis (BIA) was carried out to evaluate the financial impact of replacing the current primary immunization scheme with the hexavalent vaccine-based scheme on healthcare budget, in the context of the Peruvian Immunization Program.

\section{Methods}

\section{Current vaccination scheme (existing scenario)}

Characteristics of the pentavalent, IPV, and OPV vaccines are detailed in Supplementary Table 1 (2). 
For the purpose of the economic assessment and based on interviews with management and operational experts (MINSA budget specialist, a pediatrician of the National Institute of Child Health, and a nurse responsible of the immunization program at a vaccination center), $95 \%$ of vaccines were assumed to be administered within the Peruvian Health Service (establecimientos de salud [EESS]), with the remaining $5 \%$ administered outside of the EESS during activities such as vaccination campaigns and home visits. Vaccination uptake rates reported in the Demographic and Family Health Inquest-Endes 2017 (Encuesta Demográfica y de Salud Familiar) were also considered in the economic model: $92.4 \%, 85.7 \%$, and $77.2 \%$ for the first, second, and third pentavalent doses; $94.8 \%$ and $87.7 \%$ for the first and second IPV doses, and $78.6 \%$ for the first OPV dose (24). Given deviation from guidelines recommending administration of both pentavalent and polio vaccines during the same medical visit, based on Endes 2017, the analysis also estimated $\sim 5 \%$ of infants receiving pentavalent and polio vaccines at separate visits (24).

\section{Alternative vaccination scheme (novel intervention)}

Characteristics of the hexavalent vaccine are detailed in Supplementary Table 1 (17). As with the existing scheme, based on expert interviews, $95 \%$ of the vaccines were assumed to be administered within the EESS, with the remaining $5 \%$ administered outside of the EESS. To ensure comparability of the existing and novel scenarios, vaccination uptake rates reported for the current scheme (24) were also applied to the hexavalent vaccine.

\section{Target population}

The National Immunization Program of Peru aims to vaccinate all infants $<1$ year of age with primary doses of the pentavalent and polio vaccines. Therefore, this group represents the target population for the present cost estimations. According to the 2007 and 2017 national censuses and considering the proportion of the population not represented in these surveys, the estimated target population was 500,000 individuals (51\% male; $49 \%$ female).(25)

\section{Time horizon}

All vaccines assessed are administered within the first year of life;(2) therefore, the time horizon for the present analysis was 1 year. This will capture the majority of local and systemic adverse reactions, which usually appear within hours to days of vaccine administration (2, 26-28).

One year is sufficient to identify cases of OPV-derived polio, which has an incubation period of 4-40 days (29). While individuals with polio may require $>16$ years of rehabilitation,(30) the present analysis captures the costs associated with initial evaluation and treatment during the acute phase (first 6 months) (31).

The CMA and BIA presented in this paper follow the standard methodology for economic assessments, which are described below.

\section{CMA - Cost calculations}

CMA is a commonly used method for projecting the least costly therapeutic when, as in this case, alternative interventions have been proven to be equivalent in terms of all relevant outcomes (32). The evaluation was made from a social perspective,(33) taking into account not only healthcare costs to administer the vaccines and to treat any resulting adverse reaction, but also considering related storage costs, and the indirect social cost valuing the time of parents to fully immunize their infants (34). Average costs to fully protect an infant were calculated considering the following four sub-costs: logistical costs (including national planning, vaccine acquisition, storage, and distribution), vaccination costs (including personnel, medical equipment, devices and supplies, infrastructure, medical support services, and administrative expenses), adverse reaction costs (including the cost to identify, confirm, and treat local and systemic reactions and OPV-derived polio), and social costs (the value of caretaker's time for medical services and transportation). The average considered all the scenarios by which the child could be fully immunized, and that the same child could experience all types of adverse reactions, because the occurrence of one reaction is independent from the others. Costs are reported in US dollars (USD, \$), with \$1 equal to S/ 3.374 Peruvian Soles (average accounting exchange rate reported on December 31, 2018 by the Peruvian Superintendence of Banks, Insurance and Private Pension Fund Administrators [Superintendencia de Banca, Seguros y AFP]) (35). Additional cost calculation methods are included in the Supplementary Appendix.

\section{BIA - Total cost estimation}

BIAs are complementary analyses that provide an estimation of the financial impact of adopting a novel intervention compared with maintaining the existing scenario $(36,37)$. The present BIA was carried out in line with recommendations from the International Society for Pharmacoeconomics and Outcomes Research (ISPOR), (38) adopting MINSA's perspective. This entity is the governing body of the Peruvian National Immunization Program, responsible for ensuring the effective use of the program budget allocated by the Ministry of Economy and Finances. The BIA assessed the financial impact of replacing the current National Immunization Program primary vaccination scheme (pentavalent vaccine plus IPV and OPV; existing scenario) with the alternative vaccination scheme (the hexavalent vaccine only; novel intervention).

To extend the costs borne by the payer to implement the national immunization strategy, unitary costs previously calculated - with the exception of social costs - were considered and multiplied by the number of infants in the target population. For each vaccination scheme, the annual cost was calculated as a sum of the following three sub-costs: logistical, vaccination, and treatment of adverse reaction costs. For logistical cost estimations, vaccination of the entire target population was assumed. For all other sub-costs, only the applicable proportions of the target population were considered in calculations, according to the immunization or clinical variants identified. Finally, the annual costs of each vaccination scheme were compared to establish the estimated budgetary impact of the alternative scheme.

Methods for cost calculations and sensitivity analysis can be found in online supplementary methods.

\section{Ethics}

We did not submit this study proposal for ethics committee review as no human subjects were involved. Such is the requirement stated by Peruvian regulations, according to the Technical Document: "Ethical Considerations for Health Research with Human Beings", approved by Ministerial Resolution No.

Page $3 / 11$ 
233-2020-MINSA. We used de-identified secondary information, obtained from open access online platforms or via request for information to the corresponding public entities. Thus, all data is anonymous, ensuring our compliance with the "Personal Data Protection Law" and its complementary regulations (Law N² 29733), approved by Supreme Decree No. 003-2013-JUS.

\section{Results}

\section{Cost-minimization analysis}

The estimated total cost of fully protecting one child using the hexavalent vaccine would be $8.7 \%$ higher than the cost required under the current scheme, increasing from $\$ 116.27$ to $\$ 126.42$. When considering this total by cost category, vaccination costs were the main driver for this increase, with the other components representing cost savings (Table 1).

Table 1

\begin{tabular}{|c|c|c|c|}
\hline Cost variable & Current scheme & Alternative scheme & $\%$ Difference \\
\hline Logistical costs & 5.80 & 2.33 & $-59.8 \%$ \\
\hline Vaccination costs & 60.86 & 98.66 & $+62.1 \%$ \\
\hline Cost of treatment for adverse reactions & $11,293.89$ & 28.22 & $-99.8 \%$ \\
\hline Cost of treatment of common adverse reactions & 37.75 & 28.22 & $-25.3 \%$ \\
\hline Cost of treatment of OPV-derived polio & $11,256.14$ & - & $-100.0 \%$ \\
\hline Social cost of lost time & $1,289.65$ & 17.50 & $-98.6 \%$ \\
\hline Cost of time lost due to vaccination & 9.31 & 8.22 & $-11.7 \%$ \\
\hline Cost of time lost due to treatment of common adverse reactions & 12.37 & 9.28 & $-25.0 \%$ \\
\hline Cost of time lost due to OPV-derived polio & $1,267.97$ & - & $-100.0 \%$ \\
\hline Total & 116.27 & 126.42 & $+8.7 \%$ \\
\hline \multicolumn{4}{|c|}{$\begin{array}{l}\text { USD, \$1 equal to S/ } 3.374 \text { Peruvian Soles (average accounting exchange rate reported on December 31, } 2018 \text { by the Peruvian Superintendence of Banks } \\
\text { Insurance and Private Pension Fund Administrators [Superintendencia de Banca, Seguros y AFP]).(35) }\end{array}$} \\
\hline
\end{tabular}

\section{Vaccination costs}

The hexavalent vaccine scheme would increase direct vaccine administration costs from $\$ 60.86$ to $\$ 98.66$ (+ $62.1 \%)($ Table 1$)$. The greatest contributor to this higher cost was the mean acquisition cost of the vaccine $(\$ 20.6[\sim \mathrm{S} / 69.5]$ per dose, compared with $\$ 1.1, \$ 5.3$, and $\$ 0.1[\sim \mathrm{S} / 3.7, \mathrm{~S} / 17.9$, and S/ 0.4] for the pentavalent vaccine, IPV, and OPV, respectively).(23) Therefore, the acquisition cost of vaccines to protect one infant under the current scheme was $\$ 13.98$ ( S/ 47.16), compared with $\$ 61.80$ ( S/ 208.51) using the hexavalent vaccine.

Costs varied according to where the vaccine was administered. Under the alternative scheme, if received in the EESS, the cost would be increased from $\$ 57.28$ to $\$ 97.00$ (+69.3\%); if administered outside of the EESS, the cost would be reduced from $\$ 121.38$ to $\$ 115.12(-5.2 \%)$. Because this scheme only involves one vaccine (compared with three under the current), it would require less healthcare practitioner time, medical equipment and general expenses to ensure the adequate transportation of the vaccines.

Logistical costs

Logistical costs per dose were highest for IPV (\$2.20), followed by the hexavalent $(\$ 0.78)$, pentavalent $(\$ 0.46)$, and OPV (\$0.04) vaccines (Supplementary Table 4). Therefore, the logistical costs associated with protecting one infant would be lower with the alternative scheme (\$2.33) compared with the current scheme (\$5.80), representing a cost saving of $59.8 \%$ (Table 1$)$.

In addition, the alternative scheme would make use of only $4.0 \%$ of warehouse space to store the hexavalent vaccine, freeing $17.5 \%$ of the total cold chain storage space required for the National Immunization Program vaccines (Fig. 1).

\section{Adverse reaction costs}

The costs of treating a child who develops both local and systemic reactions and OPV-derived polio would be reduced by $99.8 \%$ under the alternative scheme, decreasing costs from $\$ 11,293.89$ to $\$ 28.22$ (Table 1).

The estimated cost of treating local and systemic adverse reactions in one child was $\$ 28.22$ when using the alternative scheme compared with $\$ 37.75$ with the current scheme $(-25.3 \%)$. Although both schemes can cause the same common adverse reactions, the probability of developing these types of reactions is higher under the current scheme (Supplementary Fig. 1). Furthermore, because the hexavalent vaccine eliminates the risk of OPV-derived polio, it would generate a cost saving of $\$ 11,256.14$ per child (Table 1 ). 
Social costs

In order to fully immunize their child and resolve associated complications, assuming the scenario that a child develops both types of adverse reactions, parents would spend $\sim 935$ hours less under the alternative scheme. This accounts for a reduction of 0.8 hours for vaccination activities, 2.3 hours for followup and treatment of local and systemic adverse reactions, and 932.4 hours for polio diagnosis and subsequent treatment. This would result in savings of $98.6 \%$ per child vaccinated (\$17.50 with the hexavalent vaccine vs $\$ 1,289.65$ under the current scheme) (Table 1).

When expanding this estimate for the entire target population, an overall reduction of 1,759,042 hours with the alternative scheme was calculated. Accordingly, the estimated total cost was $\$ 7,463,891$ with the hexavalent vaccine versus $\$ 9,854,066$ with the current scheme (-24.3\%). This value included a $15.7 \%$ reduction in the cost of time $(\$ 3,593,529$ vs $\$ 4,263,510)$, because of fewer vaccination appointments and fewer vaccines administered at each appointment (Supplementary Tables 5 and 6). It also accounts for a 30.7\% reduction in the cost of time linked with treatment of local and systemic adverse reactions $(\$ 3,870,361$ vs $\$ 5,587,264)$ (Supplementary Table 7), and a 100\% reduction in the cost of time to treat OPV-derived polio (no cost vs $\$ 3,291)($ Supplementary Table 8).

\section{Budget impact analysis}

The estimated total annual cost to finance the implementation of vaccination activities nationwide under the current scheme was $\$ 48,281,706$, compared with $\$ 55,744,653$ for the alternative scheme (Fig. 2). This represents a budgetary impact of $+\$ 7,462,947(+15.5 \%)$ with the alternative scheme, mainly associated with the larger direct vaccine administration costs. Substituting the current scheme with the alternative scheme would increase total annual costs associated with vaccination by $\$ 15,020,936$ (54.1\%), from $\$ 27,786,830$ to $\$ 42,807,766$ (Fig. 2; Supplementary Tables 2 and 3).

Conversely, the total annual cost to guarantee the vaccine supply chain until its arrival at the healthcare facility would be lower with the hexavalent vaccine. The estimated logistical cost per annum was $\$ 2,901,769$ for the current scheme, compared with $\$ 1,167,457$ for the alternative scheme (Fig. 2), for an annual cost saving of $59.8 \%$.

Similarly, the estimated total annual cost of treating all cases of adverse reactions was $33.1 \%$ lower with the alternative scheme $(\$ 11,769,430)$ compared with the current scheme $(\$ 17,593,106)$ (Fig. 2).

Specifically, the estimated total annual cost of treating local and systemic adverse reactions was $\$ 11,769,430$ with the hexavalent vaccine compared with $\$ 17,052,869$ under the current scheme, representing a cost saving of $31.0 \%$ (Supplementary Table 9). A lower number of vaccinated infants would experience $\geq 4$ local and/or systemic adverse reactions with the hexavalent vaccine $(83,192)$ compared with the current scheme $(313,796)$. Consequently, the cost of treating these infants with $\geq 4$ events would be reduced by $74 \%$ with the alternative scheme compared with the current scheme ( $\$ 3,425,919$ versus $\$ 13,161,210$, respectively). The use of the hexavalent vaccine would avoid all costs associated with OPV-derived polio (estimated at $\$ 540,238$ per annum under the current scheme) (Supplementary Table 10).

\section{Sensitivity analysis}

Of the scenarios analyzed, only those involving a variation in the hexavalent vaccine acquisition cost showed a significant impact on the total cost of the alternative scheme. Varying only the hexavalent vaccine price per dose resulted in a total annual cost reduction to $\$ 42,060,948$, when the cost dropped by $49 \%$ ( $\$ 10.1$ per dose); and an increase to $\$ 69,428,358$, when the cost rose by $51 \%$ (\$31.1 per dose) (Fig. 3A; scenario 1). Variations in case volume and vial weight did not result in considerable changes in total costs estimated in the basic scenario (Fig. 3B; scenario 2, and 3C; scenario 3). When the hexavalent vaccine acquisition cost per dose and case volume were assumed to vary, the estimated total annual cost was significantly changed (Fig. 3D; scenario 4).

\section{Discussion}

CMA and BIA analyses of replacing the current scheme with a hexavalent vaccine resulted in a net increase in costs of $8.7 \%$ and $15.5 \%$, respectively. This was primarily driven by the higher acquisition cost per dose of the hexavalent vaccine compared with the other three vaccines, which impacted considerably the healthcare costs to administer the vaccine. When analyzing other activities related to the immunization process, savings were found on logistics costs and costs associated with treatment of adverse reactions.

Compared with the CMA, the BIA estimated a smaller reduction in costs related to treatment of adverse reactions in the alternative scheme versus the current scheme. This is likely because of the low risk of developing vaccine-derived polio across the entire population, minimizing the budget impact of this costly adverse reaction. The CMA also considered the broader perspective of social costs, showing that the alternative scheme would result in an overall saving of time parents spent on medical appointments to immunize their child and treating any adverse reaction, translating into a total cost saving of $24.3 \%$. In this sense, it would be of interest to analyze other indirect impacts of substituting the current scheme with the hexavalent vaccine.

\section{Logistics}

Replacement of the current vaccination scheme with the hexavalent vaccine was found to result in a logistical cost saving of $59.8 \%$ (equivalent in total to more than $\$ 1.7$ million), as well as freeing of $~ 18.0 \%$ of the required Peruvian vaccines storage capabilities. This additional benefit is associated with the smaller volume and weight of the hexavalent vaccine compared with the pentavalent vaccine, IPV, and OPV combined.

Freeing transportation and storage space would increase the efficiency of the supply chain and avoid bottlenecks caused by an insufficient capacity to receive supplies at a national and local level (39). 
The smaller hexavalent vaccine dimensions could potentially generate savings during vaccination campaigns outside healthcare facilities, particularly in rural areas where cold storage space may be more limited and vaccination campaigns more frequent because of geographic dispersion.

\section{Local and systemic adverse reactions}

As reflected by the $33.1 \%$ lower adverse reaction costs (equivalent in total to $\sim \$ 5.8$ million), the alternative scheme is expected to be associated with fewer events than the current scheme. In terms of local and systemic reactions, this effect is largely due to the aP component of the hexavalent vaccine, $(17,40)$ which replaces the WP component included in the pentavalent vaccine of the current scheme (2). WP is more reactogenic than aP, and has a higher incidence of injection site and systemic adverse reactions, such as fever, erythema, swelling, and drowsiness $(41,42)$. A previous study carried out in Peru found that the hexavalent vaccine results in $20 \%$ fewer episodes of fever $>38^{\circ} \mathrm{C}$ and a considerably lower incidence of local and systemic reactions than a vaccination scheme based on a pentavalent vaccine and OPV (42).

\section{Vaccine-derived polio}

A further contributor to the reduced adverse reaction costs associated with the hexavalent vaccine is the elimination of the risk of OPV-derived polio. Although rare,(43) acute paralytic polio is an extremely serious and debilitating disease, with no cure and mortality rates of 5-10\% (8). The last recorded case of wild poliovirus-derived disease in the Americas occurred in 1991 (43). However, in Peru, 81 cases of OPV-derived acute flaccid paralysis were investigated in 2011 , with three considered paralytic (43). In 2017, according to the MINSA National Centre of Disease Epidemiology, Prevention and Control, 55 cases of suspected acute flaccid paralysis were notified in Peru,(44) with one case confirmed (45). Given that identifying, monitoring, and confirming suspected polio cases, as well as treating confirmed cases, entail a substantial cost to the Peruvian Government (estimated as $\sim \$ 0.5$ million [S/ 1.8 million] per annum in the current study), the ability of the hexavalent vaccine to replace OPV and, thereby, eradicate the risk of vaccine-associated polio, is a substantial benefit.

OPV also has the potential to cause polio outbreaks in areas previously free of the disease(46). The current position of the WHO is that successful eradication of polio depends upon complete withdrawal of OPV vaccines (47). The Latin American Society for Pediatric Infectious Disease (Sociedad Latinoamericana de Infectología Pediátrica) recommends a regional transition away from OPV and towards IPV (48). Many national healthcare services have already discontinued use of OPV altogether, including the US, Uruguay, and Chile $(12,49,50)$. Including the hexavalent vaccine in the National Immunization Program of Peru would be an option to achieve this objective.

In addition to the aforementioned cost advantages, reducing adverse reaction rates and eliminating OPV-derived polio by use of the alternative scheme would decrease the amount of time a healthcare professional must dedicate to solve adverse reactions, as well as time spent by parents caring for a sick child.

As a combination vaccine, the hexavalent vaccine could reduce the risk of vaccination sequence disruption and delayed vaccination, contributing to improved vaccination coverage. However, more integrated vaccination schemes may be more sensitive to supply interruptions, negatively affecting vaccination coverage. Hence, a balance between both effects should be considered.

\section{Limitations}

From a payer perspective, CMAs and BIAs are essential for the comprehensive economic assessment of a novel healthcare intervention, and are important evidence for reimbursement authorities (38). Nevertheless, while conducted in line with ISPOR recommendations using the most appropriate data sources available, the present analysis was based on a number of assumptions and results should be interpreted as best estimates of real-world outcomes. For example, the vaccine uptake rates for the hexavalent vaccines and the current scheme were assumed to be the same; however, this may not be representative of clinical practice and requires further investigation. In addition, the study had a limited time horizon of 1 year and only considered vaccine effects in infants $<1$ year of age; thus, any long-term effects (such as long-term costs associated with polio rehabilitation and the long-term economic return of disease prevention at a population level) were not captured.

It should also be noted that BIAs are not intended to capture aspects such as productivity and costs outside of the healthcare system (38). Although this study incorporated the differences in cost of time society would assume under both scenarios, it does not recognize other intangible impacts, such as the potential effects on the utilization of human and physical resources.

\section{Conclusions}

According to the present study, including the hexavalent vaccine into the National Immunization Program of Peru in place of the current vaccination scheme for infants $<1$ year of age would increase the public financial budget of the government by $15.5 \%$. Despite the significant reduction of logistical and adverse reaction costs, it would represent larger vaccine administration costs.

Incorporating the indirect costs associated with time spent by parents to complete the immunization program would reduce the budgetary impact to $8.7 \%$ with the use of the hexavalent vaccine, thereby demonstrating the social value of the alternative scheme. This merits consideration by government bodies, and future studies investigating such benefits would be informative.

\section{Abbreviations}

aP: Acellular pertussis

BIA: Budgetary impact analysis

CMA: Cost-minimization analysis 
EESS: establecimientos de salud

IPV: Inactivated polio vaccine

ISPOR: International Society for Pharmacoeconomics and Outcomes Research

Hib: Haemophilus influenzae type B

MINSA: Ministerio de Salud de Perú

OPV: Oral polio vaccine

WHO: World Health Organization

wP: Whole cell pertussis

\section{Declarations}

\section{Ethics approval and consent to participate}

We did not submit this study proposal for ethics committee review as no human subjects were involved. Such is the requirement stated by Peruvian regulations, according to the Technical Document: "Ethical Considerations for Health Research with Human Beings", approved by Ministerial Resolution No. 233-2020-MINSA. We used de-identified secondary information, obtained from open access online platforms or via request for information to the corresponding public entities. Thus, all data is anonymous, ensuring our compliance with the "Personal Data Protection Law" and its complementary regulations (Law N² 29733), approved by Supreme Decree No. 003-2013-JUS.

\section{Consent for publication}

All authors approved the version to be published

\section{Availability of data and materials}

All data generated or analyzed during this study are included in this published article [and its supplementary information files].

\section{Competing interests}

JGLY is an employee of Sanofi Pasteur and may hold shares and/or stock options in the company; JS, AS, and MLR have nothing to disclose.

\section{Funding}

Funding for the cost-minimization and budget impact analyses was provided by Sanofi Pasteur. Medical writing support for this manuscript was also funded by Sanofi Pasteur. However, the funders had no role in the design, data collection, analysis or elaboration of the study.

\section{Authors' contributions}

JS, AS and JGLY contributed for conceptual design and the interpretation of the study. MLR participated in data collection and analysis, costs estimations and interpretation of final results. All authors contributed to the critical revision of the article and final approval of the version to be published.

\section{Acknowledgements}

Carlos Gazzo provided expert guidance regarding logistic costing. Gonzalo Moromizato collaborated as part of the Videnza team. Medical writing support was provided by Helen Sims at Chameleon Communications International and Saili Dharadhar (Sanofi). Editorial assistance and manuscript coordination were provided by Roopsha Brahma, PhD on behalf of Sanofi Pasteur.

\section{References}

1. Ministerio de Salud (MINSA) Republica del Peru. Tercer informe intervención publíca evaluada: servicio de vacunación2011. Available from:https://www.mef.gob.pe/contenidos/presu_publ/ppr/eval_indep/2010_informe_final_VACUNACIONES.pdf.

2. Ministerio de Salud (MINSA) Republica del Peru. NTS No 141 - MINSA/2018/DGIESP norma técnica de salud que establece el esquema nacional de vacunación (Resolución Ministerial No 719-2018/MINSA)2018.

3. World Health Organization. Diphtheria 2018 [updated September 20, 2018. Available from: https://www.who.int/immunization/diseases/diphtheria/en/.

4. World Health Organization. Tetanus 2020 [Available from: https://www.who.int/health-topics/tetanus/\#tab=tab_1.

5. World Health Organization. Hepatitis B 2019 [updated July 18, 2019. Available from: https://www.who.int/news-room/fact-sheets/detail/hepatitis-b.

6. World Health Organization. Pertussis 2020 [Available from: https://www.who.int/health-topics/pertussis\#tab=tab_1. 
7. World Health Organization. Haemophilus influenzae type b (Hib) 2020 [Available from: https://www.who.int/ith/diseases/HiB/en/.

8. World Health Organization. Poliomyelitis 2019 [updated July 22, 2019. Available from: https://www.who.int/news-room/fact-sheets/detail/poliomyelitis.

9. World Health Organization. Hexaxim: vaccine name and dosage form 2015 [updated February 10, 2015. Available from:

https://www.who.int/immunization_standards/vaccine_quality/pq_284_hexaxim_SP_1dose_vial/en/\#: :text=Vaccine\%20Trade\%20Name\%3A\%20Hexaxim,Mi

10.Santos-Lima E, B'Chir S, Lane A. Combined immunogenicity data for a new DTaP-IPV-Hep B-PRP-T vaccine (Hexaxim) following primary series administration at 2, 4, 6 months of age in Latin America. Vaccine. 2013,31(9):1255-8.

11.Tregnaghi MW, Zambrano B, Santos-Lima E. Immunogenicity and safety of an investigational hexavalent diphtheria-tetanus-acellular pertussis-inactivated poliovirus-hepatitis B-Haemophilus influenzae B conjugate combined vaccine in healthy 2-, 4-, and 6-month-old Argentinean infants.Pediatr Infect Dis J.

2011;30(6):e88-96.

12.Ministerio de Salud de Chile. Programa nacional de inmunizaciones. Calendario de vacunación 2019 Santiago, Chile2019 [Available from:https://www.minsal.cl/programa-nacional-de-inmunizaciones/.

13.Wang S, Tafalla M, Hanssens L, Dolhain J. A review of Haemophilus influenzae disease in Europe from 2000-2014: challenges, successes and the contribution of hexavalent combination vaccines. Expert Rev Vaccines. 2017;16(11):1095-105.

14.Government of Canada. Canada's provincial and territorial routine (and catch-up) vaccination routine schedule programs for infants and children 2019 [Available from: https://www.canada.ca/en/public-health/services/provincial-territorial-immunization-information/provincial-territorial-routine-vaccinationprograms-infants-children.html.

15.Organización Panamericana de la Salud. Esquema nacional de vacunación de Panamá, año 20192019 [Available

from:https://www.paho.org/pan/index.php?option=com_docman\&view=document\&layout=default\&alias=429-esquema-nacional-de-vacunacion-de-panamaano-2019\&category_slug=rostros-voces-y-lugares\&ltemid=224.

16.Ministerio de Salud (MINSA) Republica del Peru. Registro sanitario de productos farmaceuticos (BE00884) 2017 [Available

from:http://www.digemid.minsa.gob.pe/ProductosFarmaceuticos/principal/pages/Default.aspx.

17.Sanofi Pasteur. Summary of Product Characteristics. 2017.

18.Gary HE, Jr., Smith B, Jenks J, Ruiz J, Sessions W, Vinje J, et al. Failure to detect infection by oral polio vaccine virus following natural exposure among inactivated polio vaccine recipients. Epidemiol Infect. 2008;136(2):180-3.

19.Fu R, Altamirano J, Sarnquist CC, Maldonado YA, Andrews JR.Assessing the risk of vaccine-derived outbreaks after reintroduction of oral poliovirus vaccine in postcessation settings. Clin Infect Dis. 2018;67(suppl_1):S26-S34.

20.Maman K, Zollner Y, Greco D, Duru G, Sendyona S, Remy V. The value of childhood combination vaccines: from beliefs to evidence. Hum Vaccin Immunother. 2015;11(9):2132-41.

21.MacDonald SE, Schopflocher DP, Vaudry W. Parental concern about vaccine safety in Canadian children partially immunized at age 2: a multivariable model including system level factors. Hum Vaccin Immunother. 2014;10(9):2603-11.

22.Gavi: The Vaccine Alliance. Combination vaccines: Why and how? 2016.

23.Pan American Health Organization. Programa ampliado de inmunizaciones precios de las vacunas para el año2018. Available from:https://www.paho.org/hq/index.php?option=com_docman\&task=doc_download\&gid=51464\&lang=es.

24.Instituto Nacional de Estadística e Informática. Peru encuesta demográfica y de salud familiar-ENDES 2017 [Internet]2018. Available from:https://www.inei.gob.pe/media/MenuRecursivo/publicaciones_digitales/Est/Lib1525/index.html.

25.Instituto Nacional de Estadística e Informática (INEI). Perú resultados difinitivos de los censos nacionales 2017: Tomo I2018.

26.World Health Organization. Vaccine safety basics module 3: adverse events following immunization 2019 [Available from: https://vaccine-safetytraining.org/classification-of-aefis.html.

27.Vigo A, Costagliola G, Ferrero E, Noce S. Hypotonic-hyporesponsive episodes after administration of hexavalent DTP-based combination vaccine: a description of 12 cases. Hum Vaccin Immunother. 2017;13(6):1-4.

28. Mallet E, Fabre P, Pines E, Salomon H, Staub T, Schodel F, et al. Immunogenicity and safety of a new liquid hexavalent combined vaccine compared with separate administration of reference licensed vaccines in infants.Pediatr Infect Dis J. 2000;19(12):1119-27.

29.Ministerio de Salud (MINSA) Republica del Peru. Directiva Sanitaria No 059-MINSA/DGE-V-01: Directiva Sanitaria Para La Vigilancia Epidemiológica De Poliomielitis /Parálisis Flácida Aguda2015.Available from: 
https://cdn.www.gob.pe/uploads/document/file/373711/Directiva_sanitaria_para_la_vigilancia_epidemiol\%C3\%B3gica_de_poliomielitispar\%C3\%A1lisis_fl\%CE 31433-3e9hij.pdf.

30.Naqvi AA, Naqvi SBS, Zehra F, Verma AK, Usmani S, Badar S, et al. Estimation of the direct cost of poliomyelitis rehabilitation treatment to pakistani patients: a 53-year retrospective study. Applied health economics and health policy. 2018;16(6):871-88.

31.World Health Organization. Management of poliomyelitis2015. Available from:

http://www.euro.who.int/_data/assets/pdf_file/0011/275798/Management-of-Poliomyelitis_Eng_LLV.pdf?ua=1.

32.CADTH Methods and Guidelines. Guidelines for the economic evaluation of health technologies: Canada2017; 1.0. Available from: https://www.cadth.ca/sites/default/files/pdf/guidelines_for_the_economic_evaluation_of_health_technologies_canada_4th_ed.pdf.

33.Robinson R. Costs and cost-minimisation analysis. BMJ. 1993;307(6906):726-8.

34.World Health Organization. Economic aspects of drug use (pharmacoeconomy). Introduction to drug utilization research. Oslo, Norway2003. p. 26-8.

35.United States Security and Exchange Commission. Annual report pursuant to section 13 or 15 (d) of the securities exchange act of 1934 for the fiscal year ended December 31, 20182018.Available from:https://www.sec.gov/Archives/edgar/data/1221029/000161577419006749/s117247_20f.htm.

36.Ulises Garay O, Caporale JE, Pichón-Riviere A, García Martí S, Mac Mullen M, Augustovski F. El análisis de impacto presupuestario en salud: puesta al día con un modelo de abordaje genérico.Revista Peruana de Medicina Experimental y Salud Publica. 2011;28:540-7.

37.US Department of Veterans Affairs. Budget impact analysis 2019 [Available from: https://www.herc.research.va.gov/include/page.asp?id=budget-impactanalysis.

38.Sullivan SD, Mauskopf JA, Augustovski F, Jaime Caro J, Lee KM, Minchin M, et al. Budget impact analysis-principles of good practice: report of the ISPOR 2012 Budget Impact Analysis Good Practice II Task Force. Value in health : the journal of the International Society for Pharmacoeconomics and Outcomes Research. 2014;17(1):5-14.

39. Haidari LA, Wahl B, Brown ST, Privor-Dumm L, Wallman-Stokes C, Gorham K, et al. One size does not fit all: the impact of primary vaccine container size on vaccine distribution and delivery. Vaccine. 2015;33(28):3242-7.

40.Mahmood K, Pelkowski S, Atherly D, Sitrin RD, Donnelly JJ. Hexavalent IPV-based combination vaccines for public-sector markets of low-resource countries. Hum Vaccin Immunother. 2013;9(9):1894-902.

41.Patterson J, Kagina BM, Gold M, Hussey GD, Muloiwa R. Comparison of adverse events following immunisation with acellular and whole-cell pertussis vaccines: a systematic review.Vaccine. 2018;36(40):6007-16.

42.Macias M, Lanata CF, Zambrano B, Gil Al, Amemiya I, Mispireta M, et al.Safety and immunogenicity of an investigational fully liquid hexavalent DTaP-IPVHep B-PRP-T vaccine at two, four and six months of age compared with licensed vaccines in Latin America.Pediatr Infect Dis J. 2012;31(8):e126-32.

43.Ministerio de Salud (MINSA) Republica del Peru. Informe sobre la situación de la poliomielitis en el Perú [Internet]2011. Available from:http://www.minsa.gob.pe/portada/archivos/informe_poliomielitis.pdf.

44.Ministerio de Salud (MINSA) Republica del Peru. Boletín epidemiológico del Perú contenido: volumen 27 - SE 23 [Internet]2018. Available from:https://www.dge.gob.pe/portal/docs/vigilancia/boletines/2018/23.pdf.

45.Centro Nacional de Epidemiología PyCdEC-P. Poliomielitis aguda (Parálisis flácida aguda) por grupos etareos a nivel distrital. DISA Cusco. Año 2017.2020. Available from:https://www.dge.gob.pe/salasituacional/sala/index/2_TablaCasostotal/81.

46.Grassly NC. The final stages of the global eradication of poliomyelitis. Philos Trans R Soc Lond B Biol Sci. 2013;368(1623):20120140.

47.World Health Organization. Seventy-second world health assembly: polio eradication report by the director-general (A72/9) [Internt]2019.Available from:https://apps.who.int/gb/ebwha/pdf_files/WHA72/A72_9-en.pdf.

48.Falleiros-Arlant LH, Avila-Agüero ML, Brea del Castillo J, Marino C. El desafío del cambio de la vacuna inactivada contra poliomielitis en América Latina: declaración de la Sociedad Latinoamericana de Infectología Pediátrica (SLIPE). Revista chilena de infectología. 2014;31:590-6.

49.Ministerio de Salud Pública de Uruguay. Programa nacional de vacunas. Esquema de vacunación vigente 2018 [Available from:https://www.gub.uy/ministerio-salud-publica/comunicacion/publicaciones/vacunas.

50.US Department of Health and Human Services. Polio vaccination: what everyone should know 2018 [Available from:

https://www.cdc.gov/vaccines/vpd/polio/public/index.html.

\section{Figures}


A

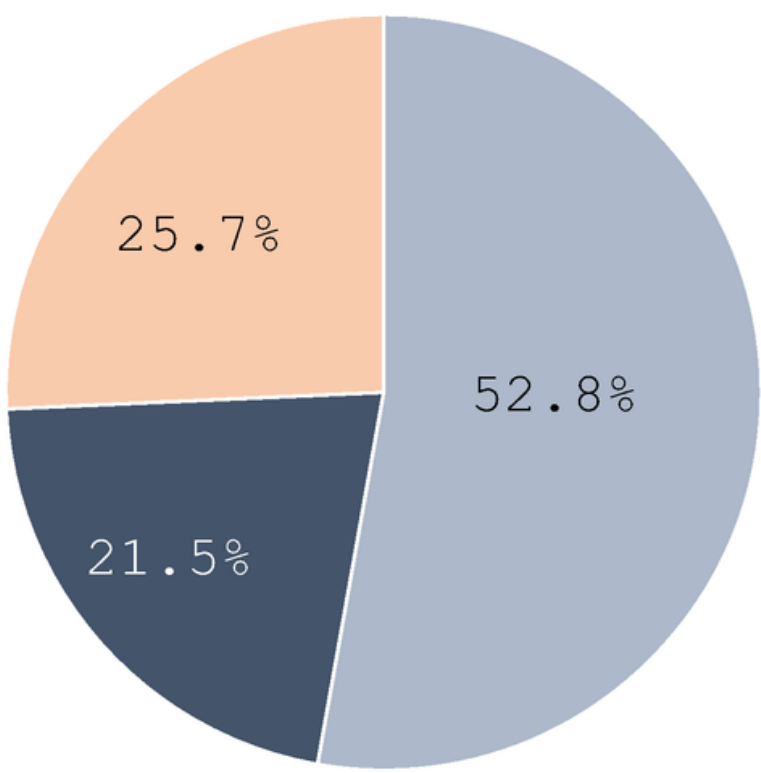

"Vaccines for children aged $\geq 1$ year

- Current scheme (pentavalent vaccine + IPV + OPV)

- Other vaccines for children aged $<1$ year
B

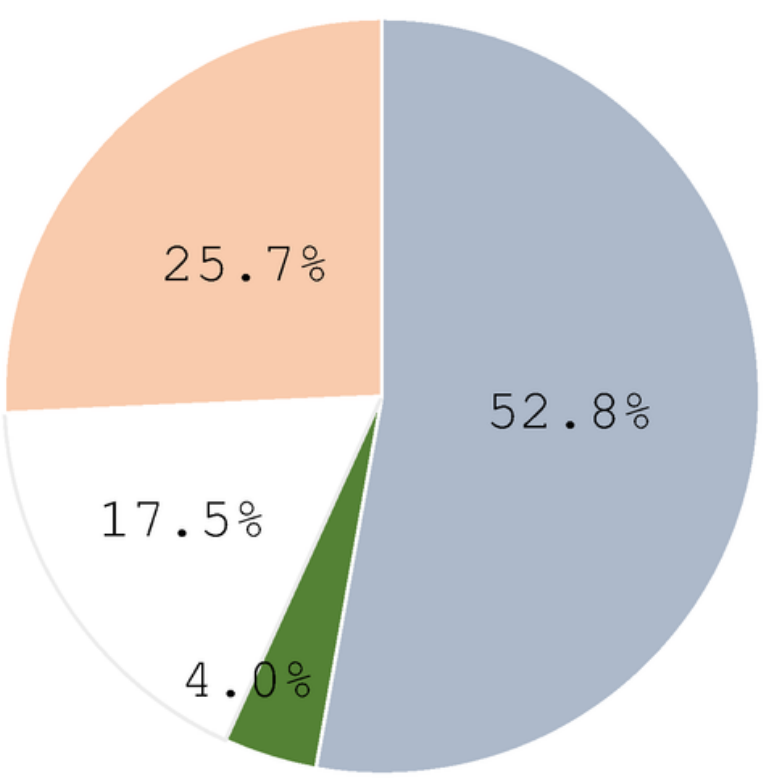

"Vaccines for children aged $\geq 1$ year

- Alternative scheme

Liberated space

- Other vaccines for children aged < 1 year

\section{Figure 1}

Storage capacity required by the vaccines, current vs alternative scheme. A) current scheme B) alternative scheme. IPV, inactivated polio vaccine; OPV, oral polio vaccine.

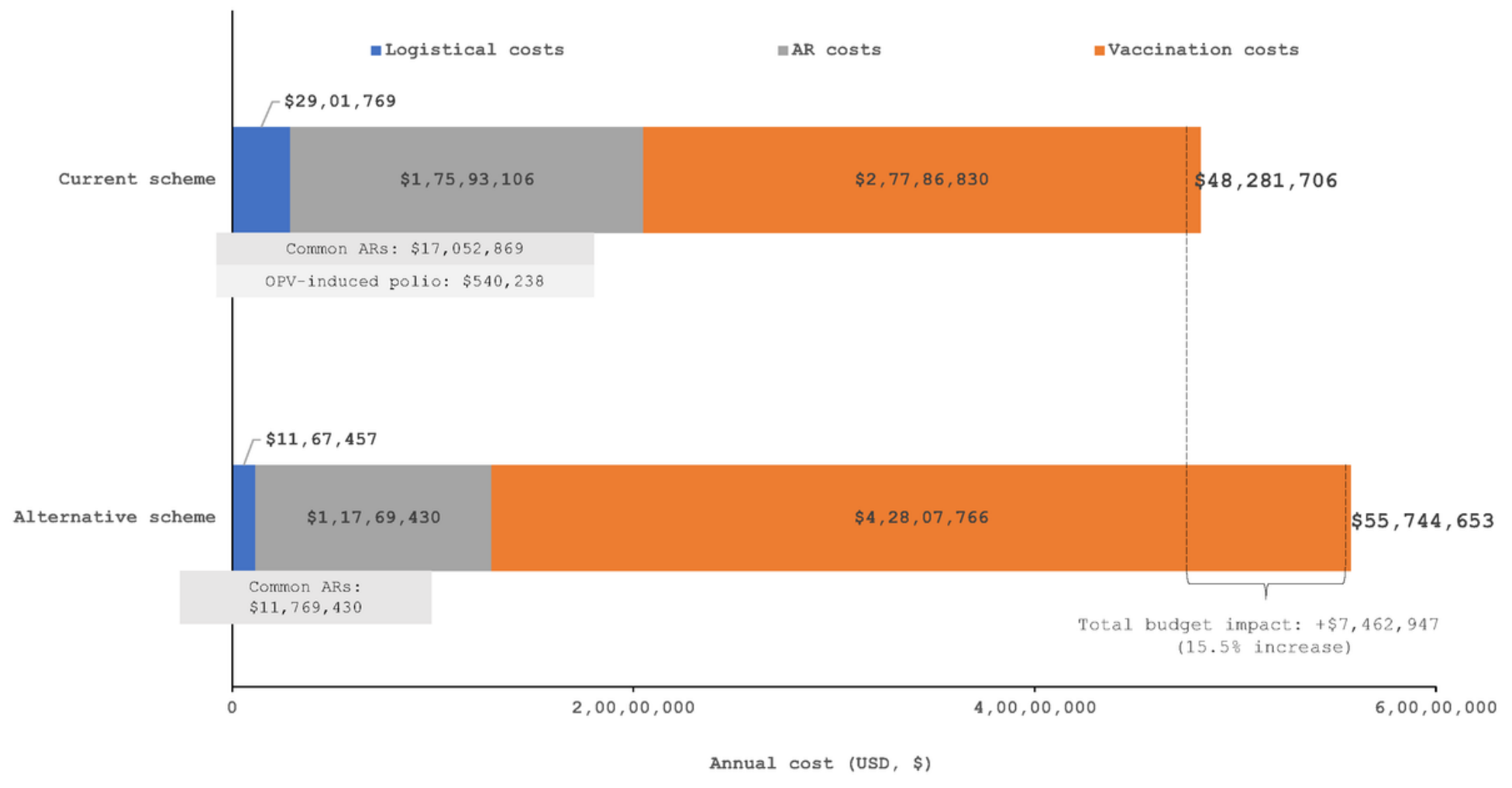

Figure 2 
Estimated total annual cost (USD, \$) associated with vaccination, according to cost category. USD, \$1 equal to S/ 3.374 Peruvian Soles (average accounting exchange rate reported on December 31, 2018 by the Peruvian Superintendence of Banks, Insurance and Private Pension Fund Administrators [Superintendencia de Banca, Seguros y AFP]).(35) ARs, adverse reactions; OPV, oral polio vaccine; USD, US dollar.
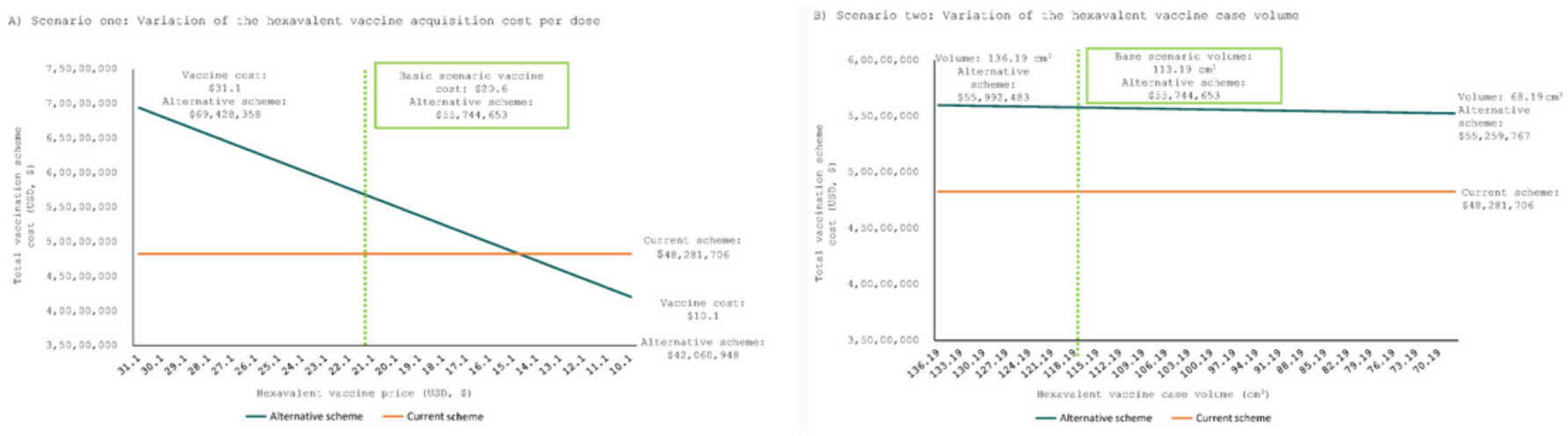

c) Scenario three: variation of the hoxavalent vaccine vial woight.

D) Scenario four: variation of the hexavalenz vaccine acquisition cost per dose and case volune
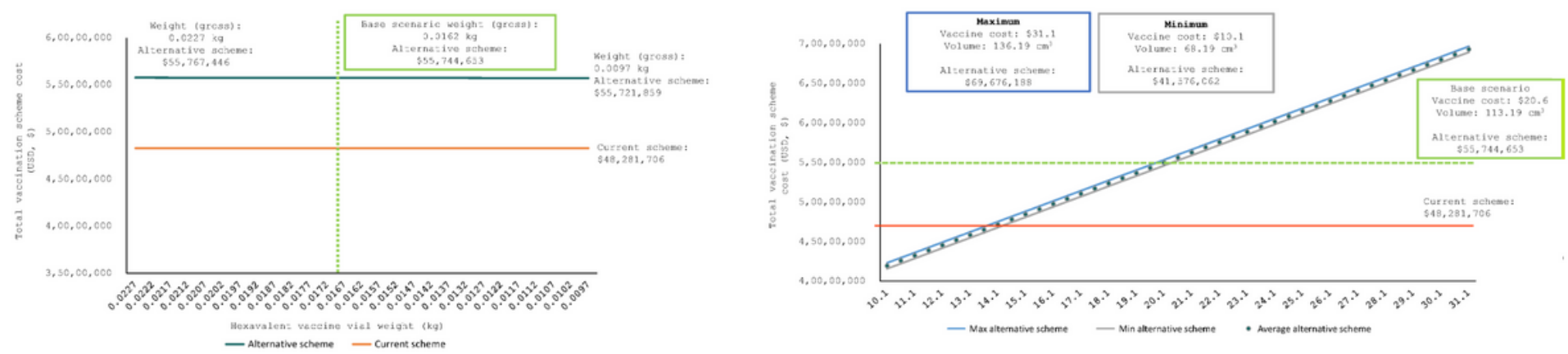

Figure 3

Variation in estimated total annual costs for the payer by sensitivity analysis scenario. A) Scenario one: Variation of the hexavalent vaccine acquisition cost per dose. B) Scenario two: Variation of the hexavalent vaccine case volume. C) Scenario three: Variation of the hexavalent vaccine vial weight per dose. D) Scenario four: Variation of the hexavalent vaccine acquisition cost per dose and case volume. * Gross weight includes the vial weight plus the weight of the packaging for proper transportation USD, US dollar.

\section{Supplementary Files}

This is a list of supplementary files associated with this preprint. Click to download.

- AdditionalFile.docx

- SupplementaryFigure.pdf 